was not affected, the posterior columns were found to be normal. The affection of the posterior bundle was in all three cases in entire accordance with the changes in the nuclei. The changes in the spinal cord were those ordinarily found. From his observations the writer believes the following conclusions are justifiable in regard to the anatomical changes in this disease.

I. The posterior bundle can, as the result of atrophy of the nuclei, become diseased. This is not a secondary degeneration, but a primary systemic affection.

2. In the posterior bundle are found short commissural fibres, the functions of which are unknown.

3. On developmental grounds and from pathologicoanatomical observations, there is a certain analogy between the ground bundle of the anterior column and the posterior longitudinal bundle.

4. Degeneration of the raphe and fillet.

\title{
A REMARK ON THE OUTER NUCLEUS OF THE FUNICULUS CUNEATUS.
}

By Dr. L. Blumenan (Neurolog. Centralbl., No. 19, I89I). Further remarks are added by this writer to his previous paper in No. 8 of the same journal concerning the inner and outer nucleus of the funiculus cuneatus, the topography of the latter and its relations to the cerebellum: Obertheines, in the recent edition of his book, speaks of the outer nucleus of the funiculus cuneatus as an inconstant group of cells situated peripherally. Blumenan believes that the cells of this nucleus belong to the two types that have been differentiated by Golgi. The nerve processes of these cells, although giving off accessory fibres, do not lose their unity after going a long distance. The nerve processes disperse as a rule lateralwards toward the restiform body and the arcuate fibres which come from the lateral columns of the cerebellum. Others of these fibres can be followed to the lateral periphery of the medulla, where further relations cannot be absolutely made out. There are also cells that send these processes inward but frequently, however, after these have passed a shorter or longer distance, they turn and go toward the periphery.

The author mentions a case of deficient development of the cerebellum which he was permitted to examine in which only a small part of the hemispheres on both sides and a rudimentary nucleus on the right side were developed. The 
inner nucleus of the funiculus cuneatus was well developed, the outer, however, showed a marked diminution of volume on both sides.

\section{CRANIOMETRY AND ITS MOST RECENT INVESTIGATIONS.}

By Prof. J. Kollman (Correspodenzblatt der Deutschen Gesellschaft für Antropologie, Ethnologie und Urgeschechte, 189r, April, May and June). (Ref. in Neurolog. Centralblatt, No. 19, I89I). Kollmann devotes the first two parts of his paper to the criticism of the recent publications of Benedikt (Kraniometrie und Kephalometrie) and Von Török (Grundzüge einer Systematischen Kraniometrie, etc.) in their mathematico- and mechanico-physical bearings. It is very difficult in a short abstract to convey to the reader the essentials of Benedikt's work and especially more so that of Török's, where the five thousand angular and linear measurements are to be considered. The human skull has no absolute unchangeable form according to Benedikt's and Von Török's ideas. It is not built like a crystal but receives the impress of, that is, it is developed according to racial peculiarities and changes. The skull follows the law of relationship in the vertebrates. Morphology and biology show only the structure of the skull. The segmental nature of the skull can not be doubted any longer and it is not to be explained by way of mathematics and mechanics.

Kollman found among Europeans two entirely different forms of facial formation, countenance as it were, that are transferred from parent to offspring. The large and small form of countenance (leptoprosop) and the short and wide (chamialprosop). For each of these standard cases he has made a countenance index after the formula

$$
\frac{\text { Breadth of zygoma } \times 100 .}{\text { Length of countenance. }}
$$

Low forms are reckoned with an index below 90, and high above 9o. With the long countenance are found high orbital sockets, small, long nose, small superior and inferior maxillary bones, small palate and narrow zygomatic arches. With the wide countenances are found low orbital cavities, short nose with wide apertures, broad and flat nasal bones, low superior maxillary, broad and wide palate, prominent cheek bones and outstanding zygomatic arches. However, in the broad as in the long countenance the anatomi- 